\title{
Analysis of meteorological factors on different stages of heavy haze pollution in Beijing, 2019
}

\author{
Ansheng Chen ${ }^{1,2, *}$ \\ ${ }^{1}$ Department of Municipal and Environmental Engineering, School of Civil Engineering, Beijing Jiaotong University, Beijing, \\ 100044, PR China \\ ${ }^{2}$ Lancaster Environment Centre, Lancaster University, Lancaster LA1 4YQ, UK
}

\begin{abstract}
Beijing occurred severe haze events in winter of recent years. To understand the extreme events, the air pollution case from 9 January to 15 January 2019 was selected. The $\mathrm{PM}_{2.5}$ concentration of 34 monitoring sites which were hourly measured, the nationwide synoptic conditions at surface and $850 \mathrm{hpa}$, the meteorological factors including temperature, wind speed and humidity and the vertical variation in Planetary boundary layer (PBL) during the case were analyzed. It is found that synoptic condition, meteorological factors and urban $\mathrm{PM}_{2.5}$ (fine particles with diameter less than $2.5 \mu \mathrm{m}$ ) concentration distribution changed regularly with time. Clean stage, transport stage, cumulative stage and dispersion stage during haze are defined in this study. Three overall research results are: (1) The synoptic variation is distinct. Beijing is alternately dominated by Siberian High-pressure and Western Pacific Subtropical High-pressure system in winter. The transport stage is with predominant Subtropical High-pressure which brings temperature and humidity rise. High humidity facilitates formation of secondary aerosols. The cumulative stage ends along with boosted Siberian High-pressure. (2) The severe haze is characterized by temperature inversion, low wind speed and high humidity, especially nearby surface, and experienced $\mathrm{PM}_{2.5}$ explosive growth. The stability of PBL structure will be strengthened with decreased PBL height, which inhibits the dispersion of pollutants. (3) The $\mathrm{PM}_{2.5}$ concentrations during different stages had different regional distribution. The southern $\mathrm{PM}_{2.5}$ concentration is much high than northern in transport stage. During dispersion stage, urban central $\mathrm{PM}_{2.5}$ is the high for the reason that buildings, vehicle exhaust and urban heat island effects all impede haze disappearing.
\end{abstract}

\section{Introduction}

Air pollution became a significant challenge in the world, especially in developing countries ([1]). Air pollution problems have been increasing adverse effects on human health and environment. About $80 \%$ of the world population lives in the environments exceeding the air quality guideline ([2]). Concentrations of air pollutants in many places can significantly increase acute and chronic negative influences on human health ([3]). Air pollution not only reduces the visibility, but also endanger geriatric respiratory and cardiovascular systems and reduces neonatal survival rate as acute reduction in lung function ([4]). Furthermore, recent studies show that the relationship between $\mathrm{PM}_{2.5}$ and $\mathrm{PM}_{10}$ (fine particles with diameter less than $10 \mu \mathrm{m}$ ) with microorganisms in the air has serious harm to humans ([5-8]).

China has been suffered from serious haze. The most serious air pollution occurred in the Beijing-Tianjin-Hebei (BTH) region. The data suggested that the daily $\mathrm{PM}_{2.5}$ concentration of BTH region even beyond $500 \mu \mathrm{g} \mathrm{m}^{-3}$ ([9]). The BTH region is one of the largest and most dynamic economic zones in northern China for the unique geographical location. This region connects North China Plain with the Inner Mongolian
Plateau. It consists of two megacities, which are Beijing and Tianjin, and 11 prefecture-level cities in Hebei Province. Rapid economic growth and urbanization are the major reasons for severe haze events which particularly occurs when coals were burning for heating in winter ([10]). Statistics results indicates that eight and seven cites in China's top ten polluted for 2014 and 2015 respectively are located in the BTH region ([11-12]).

Many precious researches about haze episodes focus on the extremely severe haze event of Beijing. Some of them commonly suggested that the severe haze has the characteristic of $\mathrm{PM}_{2.5}$ explosive growth ([13-15]). A variety of explanations had been proposed by previous researches. Zhong et al. ([13]) indicated that the variation of $\mathrm{PM}_{2.5}$ in continuous time can be divided into many periodic processes and each process contain several stages according to different $\mathrm{PM}_{2.5}$ concentration changing trends. These stages are called clean stage, transport stage, cumulative stage and dispersion stage in this study. The unfavorable meteorological condition is the major reason for severe air pollution in Beijing ([13]). Other research ([16]) carried out found that the $\mathrm{PM}_{2.5}$ occupies a very large proportion in air pollutants and contains secondary aerosols especially in heavily polluted episodes, and the composition of $\mathrm{PM}_{2.5}$ indeed varied with different meteorological conditions. Zheng et al. ([17]) found that $\mathrm{PM}_{2.5}$ concentration mainly is

*Corresponding author:16723003@bjtu.edu.cn 
caused by regional transport contribution. Southerly transport of pollutants rises significantly during the polluted episodes ([18]).

Previous studies by analyzing the atmospheric background suggested that disadvantageous meteorological effects including temperature inversion, high relative humidity, weak surface wind and vertical wind shear all substantially influenced the $\mathrm{PM}_{2.5}$ concentration, through both physical (e.g., transportation, dispersion and deposition) and chemical (e.g., the formation pathway and reaction rate of secondary aerosol) mechanism ([19-20]). High $\mathrm{PM}_{2.5}$ concentration levels accumulated further and then decrease the near ground temperature by reflecting and scattering more solar radiation, strengthening the existing temperature inversion and cooperated with weakened horizontal winds to reduce the PBL height ([13]). PBL becomes more stable and conducive to pollutant accumulation. The decrease of PBL height hindered the vertical mixing of pollutants, resulting in elevated pollution level ([17]). Hygroscopic growth of $\mathrm{PM}_{2.5}$ is also conducive for severe haze formation. In the condition of high humidity, aerosol particle size could enlarge at least 20\% through absorbing water vapor in North China ([21]). Besides these, the topography that Beijing is surrounded by mountains are favorable for the formation and subsequently growth of air pollution in the center of Beijing ([22]).

It is known that the effects of meteorological factor on $\mathrm{PM}_{2.5}$ concentration variation in Beijing is substantial especially when winter comes. The previous studies are mostly covered the BTH region. This paper will focus on the haze process in Beijing by using the $\mathrm{PM}_{2.5}$ concentration observation data of 34 monitoring sites which records severe pollution episode in January 2019 in particular from January 9 to 15 , then analyze the synoptic condition and the structure of PBL, also explore the interaction and correlation between the spatial distribution feature of $\mathrm{PM}_{2.5}$ and meteorological elements in Beijing during different stages of the haze pollution case.

\section{Data and Method}

In this study, the following data are used:

(1) The hourly $\mathrm{PM}_{2.5}$ concentration of 34 monitoring sites are from Beijing Environmental Protection Testing Center(http://www.bjmemc.com.cn/). The ground distribution of these stations observed from Google map are shown in Fig. 1, and the specific location noted by longitude and latitude are listed in Table 1.

(2) Atmospheric sounding data are observed twice daily at 0800 and 2000 Beijing time (BT), including temperature, wind speed, water vapor mixing ratio and relative humidity $(\mathrm{RH})$, measured at Beijing Observatory of which station number is 54511 in Daxing District from 1 January 2019 to 31 January 2019 (http://weather.uwyo.edu/upperair/sounding.html).

(3) Weather background map at 08:00 BT and 20:00 BT from national meteorological service are provided by the Korea Meteorological Administration (KMA) (http://222.195.136.24/forecast.html).

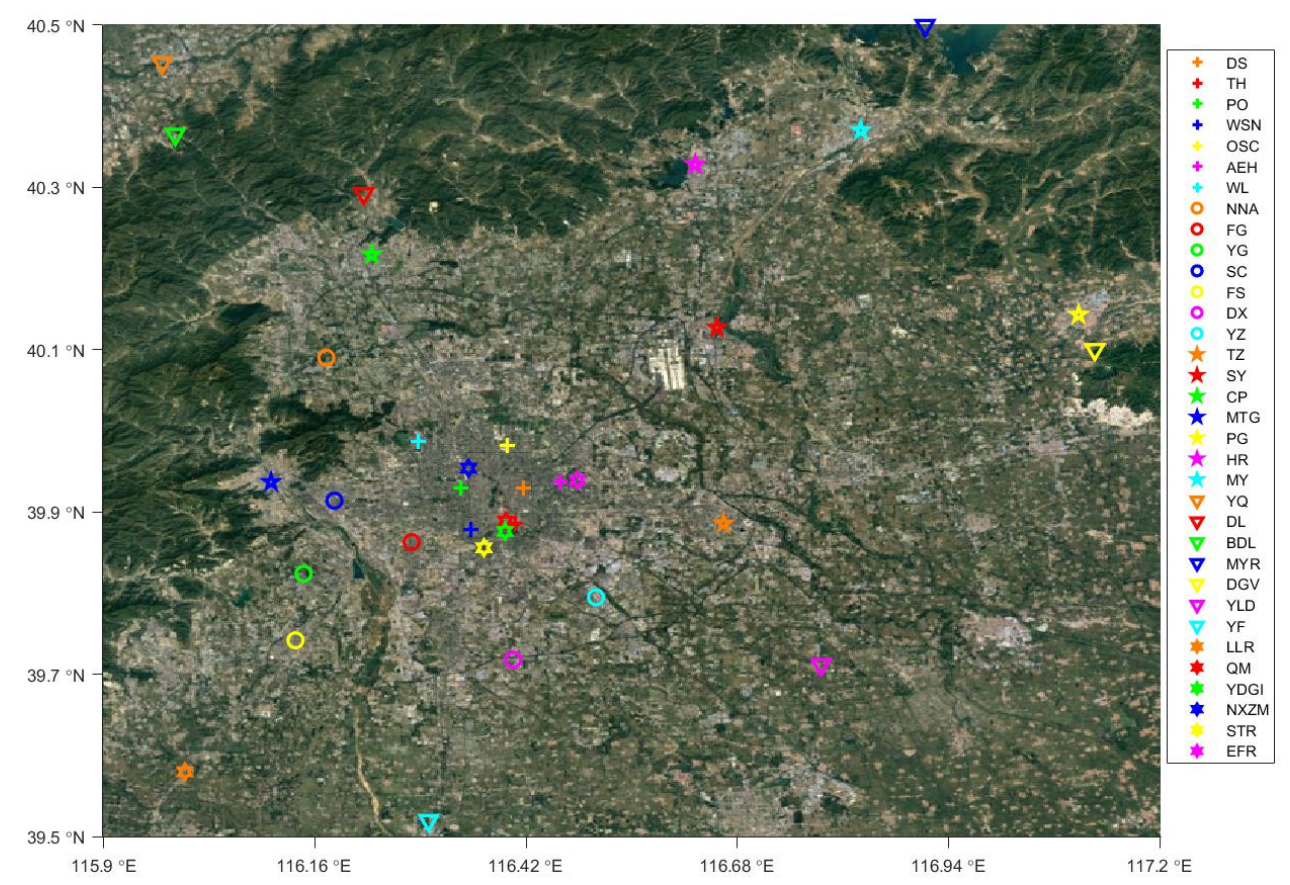

Fig. 1. The location distribution of 34 air quality monitoring stations in Beijing

Table 1. Specific location for each air quality monitoring station of 34 monitoring sites

\begin{tabular}{|c|c|c|c|}
\hline Monitoring Site & Full Name of Monitoring Site & Longitude & Latitude \\
\hline \multicolumn{4}{|c|}{ Urban Environmental Assessment Site } \\
\hline $\mathrm{DS}$ & Dongsi & 116.417 & 39.929 \\
\hline TH & Temple of Heaven, & 116.407 & 39.886 \\
\hline PO & West Park Officials & 116.339 & 39.929 \\
\hline
\end{tabular}




\begin{tabular}{|c|c|c|c|}
\hline WSN & West Wanshou Nishinomiya & 116.352 & 39.878 \\
\hline $\mathrm{OSC}$ & Olympic Sports Center & 116.397 & 39.982 \\
\hline $\mathrm{AEH}$ & Agricultural Exhibition Hall & 116.461 & 39.937 \\
\hline WL & Haidian Wanliu & 116.287 & 39.987 \\
\hline NNA & The Haidian Northern New Area & 116.174 & 40.09 \\
\hline FG & Fengtai Garden & 116.279 & 39.863 \\
\hline YG & Yungang, Fengtai & 116.146 & 39.824 \\
\hline $\mathrm{SC}$ & Shijingshan City & 116.184 & 39.914 \\
\hline \multicolumn{4}{|c|}{ Suburban Environmental Assessment Site } \\
\hline FS & Fangshan & 116.136 & 39.742 \\
\hline DX & Daxing Huangcun Town & 116.404 & 39.718 \\
\hline YZ & Yizhuang Development Zone & 116.506 & 39.795 \\
\hline $\mathrm{TZ}$ & Tongzhou New Town & 116.663 & 39.886 \\
\hline SY & Shunyi New Town & 116.655 & 40.127 \\
\hline $\mathrm{CP}$ & Changping Town & 116.23 & 40.217 \\
\hline MTG & Mentougou, Longquan Town & 116.106 & 39.937 \\
\hline PG & Pinggu town & 117.1 & 40.143 \\
\hline HR & Huairou town & 116.628 & 40.328 \\
\hline MY & Miyun Town & 116.832 & 40.37 \\
\hline YQ & Yanqing town & 115.972 & 40.453 \\
\hline \multicolumn{4}{|c|}{ Control and Region Point } \\
\hline $\mathrm{DL}$ & Dingling Mausoleum & 116.22 & 40.292 \\
\hline BDL & Badaling, Beijing Northwest & 115.988 & 40.365 \\
\hline MYR & Miyun Reservoir, Beijing Northeast & 116.911 & 40.499 \\
\hline DGV & Donggao Village, Beijing East & 117.12 & 40.10 \\
\hline YLD & Yongle Dian, Beijing Southeast & 116.783 & 39.712 \\
\hline YF & Yuyuan, Beijing South & 116.30 & 39.52 \\
\hline LLR & Liuli River, Beijing Southwest & 116.00 & 39.58 \\
\hline \multicolumn{4}{|c|}{ Monitoring Site of Traffic Pollution } \\
\hline $\mathrm{QM}$ & Qianmen East Street & 116.395 & 39.899 \\
\hline YDGI & Yongding Gate Inner Street & 116.394 & 39.876 \\
\hline NXZM & Xizhimen North Street & 116.349 & 39.954 \\
\hline STR & South Third Ring Road West & 116.368 & 39.856 \\
\hline EFR & East Fourth Ring North Road & 116.483 & 39.939 \\
\hline
\end{tabular}

\section{Results and Discussion}

\subsection{Overall analysis of air pollution}

The $\mathrm{PM}_{2.5}$ concentration general variation of Beijing in January 2019 is shown in Fig. 2. There was a severe continuous haze event occurred in Beijing during the episode from 9 January to 15 January. This episode is divided into four processes. During this episode of 7 days, the weekly average concentration of $\mathrm{PM}_{2.5}$ was about $110.4 \mu \mathrm{g} \mathrm{m}^{-3}$. The maximum hourly concentration of $\mathrm{PM}_{2.5}$ per hour reached $404.0 \mu \mathrm{g} \mathrm{m}^{-3}$ at 20:00 BT 12 January in the process $\mathrm{C}$ and the minimum was $4.2 \mu \mathrm{g}$ $\mathrm{m}^{-3}$ at 07:00 BT 15 January in the process D.

A significant feature in haze period is the dramatic hourly fluctuation of $\mathrm{PM}_{2.5}$ concentration, especially in the winter. There are 35 times that hourly $\mathrm{PM}_{2.5}$ changes range over $20 \mu \mathrm{g} \mathrm{m}^{-3}$ in January. 27 times of 35 times occurred in the process A, B, D, and D and account for $77.1 \%$ of the whole month. The maximum hourly increase reached $63.1 \mu \mathrm{g} \mathrm{m}^{-3}$ and the minimum hourly decrease was $-68.7 \mu \mathrm{g} \mathrm{m}^{-3}$. The reason for dramatic change in $\mathrm{PM}_{2.5}$ concentration is caused by clean/polluted air masses transition ([23]) and will be discussed in section 2. $\mathrm{PM}_{2.5}$ pollution was classified into four categories according to the Air Quality Index (http://kjs.mep.gov.cn/hjbhbz/bzwb/dqhjbh/jcgfffbz/2012 03/t20120302 224166.htm?COLLCC $=$ 2906016564\&): clean $\left(\mathrm{PM}_{2.5} \leq 35 \mu \mathrm{g} \quad \mathrm{m}^{-3}\right)$, slightly polluted $\left(35<\mathrm{PM}_{2.5} \leq 115 \mu \mathrm{g} \mathrm{m}^{-3}\right)$, polluted $\left(115<\mathrm{PM}_{2.5} \leq 350 \mu \mathrm{g} \mathrm{m}^{-3}\right)$, and heavily polluted $\left(\mathrm{PM}_{2.5}>350 \mu \mathrm{g} \mathrm{m} \mathrm{m}^{-3}\right)$, where $\mathrm{PM}_{2.5}$ refers to the hourly concentration. The slightly polluted, polluted, and heavily polluted levels correspond to small, moderate, and large $\mathrm{PM}_{2.5}$ peaks in Fig. 2. The process $\mathrm{C}$ experienced severe $\mathrm{PM}_{2.5}$ air pollution, reached heavily polluted level and is also called explosive growth process where the dominant component of $\mathrm{PM}_{2.5}$ is secondary aerosol ([24]). 


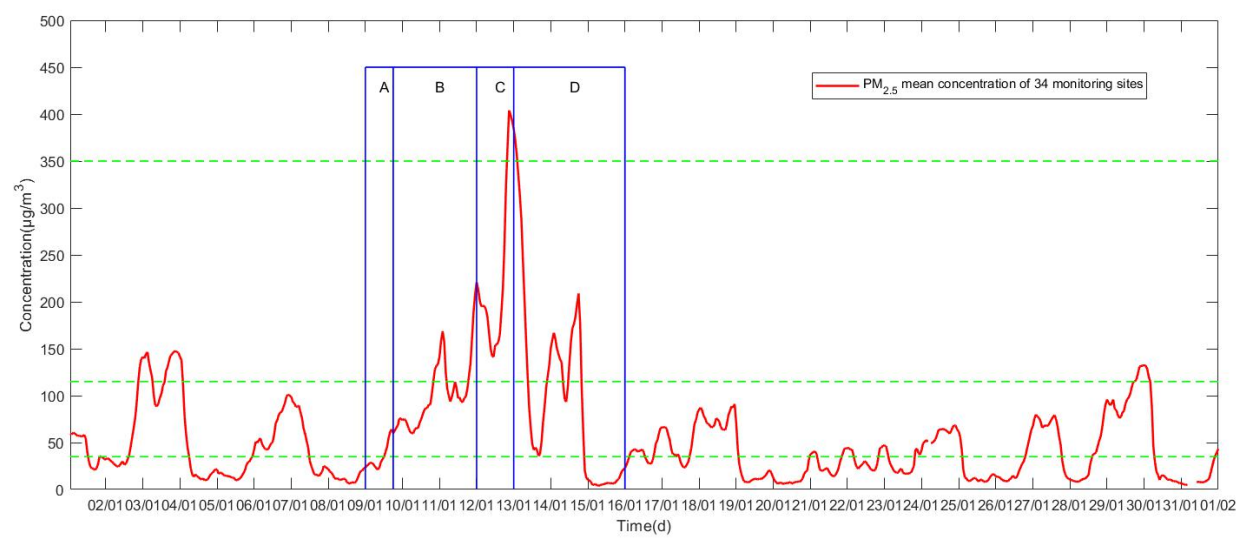

Fig. 2. Temporal variations in $\mathrm{PM}_{2.5}$ mass concentration form 1 January 2019 to 31 January 2019; process A correspond to clean stage; process $\mathrm{B}$ correspond to transport stage; process $\mathrm{C}$ correspond to cumulative stage; process $\mathrm{D}$ correspond to dispersion stage. Green dashed lines at 35,115 and $350 \mu \mathrm{g} \mathrm{m}^{-3}$ are the boundary of different pollution grades.

\subsection{Analysis of synoptic background}

Northeast anticyclone system is motivation that keeps air clean. During the clean stage, there was a strong high anticyclone system with $1047 \mathrm{hpa}$ central pressure at surface ground in the northwest of Beijing (Fig. 3a) which controlled the whole North China Plain. Beijing was located in the southeast of the high-pressure system. Therefore, the dominant wind of Beijing region was the Northeast wind, and brought cold air mass. Similarly, by analyzing the $850 \mathrm{hpa}$ map in the clean stage, Beijing was located in the east of the high-pressure system with a barometric center which was 1581gpm (geopotential meter) but was closed to the pressure center (Fig. 3e). Strong high-pressure center made the air pollutants in Beijing spread around. When the cold front passed Beijing, the strong northerly wind could cause the decrease of the temperature and the rising pressure, even might produce rain or snow. This weather phenomenon is not conducive to the suspension of air pollutants in the atmosphere. The synoptic conditions during transport stage and cumulative stage are almost opposite to clean stage.

Transport process is accompanied by weakened Siberian High-pressure system. By observing the surface pressure distribution (Fig. 3b), it is found that a high-pressure anticyclone system with a central pressure of $1033 \mathrm{hpa}$ were existing on the southwest of Beijing. Therefore, air mass flows led the southwest wind occurring in Beijing. Besides, the air mass carried industrial emissions from south of Beijing. In general, this was a process of air pollutant transport caused by synoptic condition, which resulted in the increasing concentration of $\mathrm{PM}_{2.5}$ in Beijing. During the transport stage, the western Pacific subtropical high anticyclone system at $850 \mathrm{hpa}$ with a barometric center of $1593 \mathrm{gpm}$ covered North China, resulting in a southwest wind in Beijing (Fig. 3f). A small low-pressure cyclone with a barometric center of $1459 \mathrm{gpm}$ in the west of the high-pressure system accelerated southerly wind speed, which was more conducive to the transport of pollutants from south to north. Moreover, from the isotherm line and humidity distribution, it is found that the air mass flow is warm and humid, which correspondingly increases the temperature and humidity above Beijing. These factors are all conducive to the subsequently explosive growth of $\mathrm{PM}_{2.5}$.

The combined action of several cyclones and anticyclones result in the accumulation of $\mathrm{PM}_{2.5}$. By analyzing the distribution of atmospheric pressure on the surface during cumulative stage (Fig. 3c), it is found that a Siberian high-pressure anticyclone system with 1043hpa central pressure appeared in the northwest of Beijing. At the same time, there was a high-pressure system in the southern part of Beijing with a central pressure of 1027hpa in Jiangsu Province. Therefore, the two opposite air mass interacted with each other in the Beijing and its vicinity, forming a boundary line as a shear line in this area. Relatively clean air in the north and relatively polluted air in the South gathered in urban areas of Beijing, resulting in cyclonic wind shear. This kind of shear is beneficial to the accumulation of pollutants ([13]). The low-pressure system with central pressure of 1020hpa in the northeast of Beijing and the Siberian high-pressure system had synergistic effect. This combination strengthened the Siberian high-pressure system that originally had little influence in Beijing and was more conducive to the accumulation of pollutants in Beijing. Beijing was near the low-pressure trough, where air flow was from southwest, southeast and northwest converge. The $850 \mathrm{hPa}$ distribution was similar to the surface pressure (Fig. 3g). Similarly, there was a high-pressure anticyclone system with a barometric center of $1538 \mathrm{gpm}$ in the west of Beijing and a warm high-pressure anticyclone system in the south of the West Pacific with a barometric center of $1563 \mathrm{gpm}$. The high-pressure system in the west formed a northerly wind in Beijing, while the high-pressure system in the South formed a southerly wind in Beijing. Their combined action caused the isobaric line over Beijing to become sparse and the airflow movement was slow accordingly. The general trend of air mass flow was from southwest to northeast, which may be caused by the low-pressure system with a pressure center of $1407 \mathrm{gpm}$ in the northeast. This movement trend will lead to the increase of temperature and humidity in the adjacent region, which is conducive to the enhancement of inversion temperature and high humidity, and accelerates the explosive growth of $\mathrm{PM}_{2.5}$. 


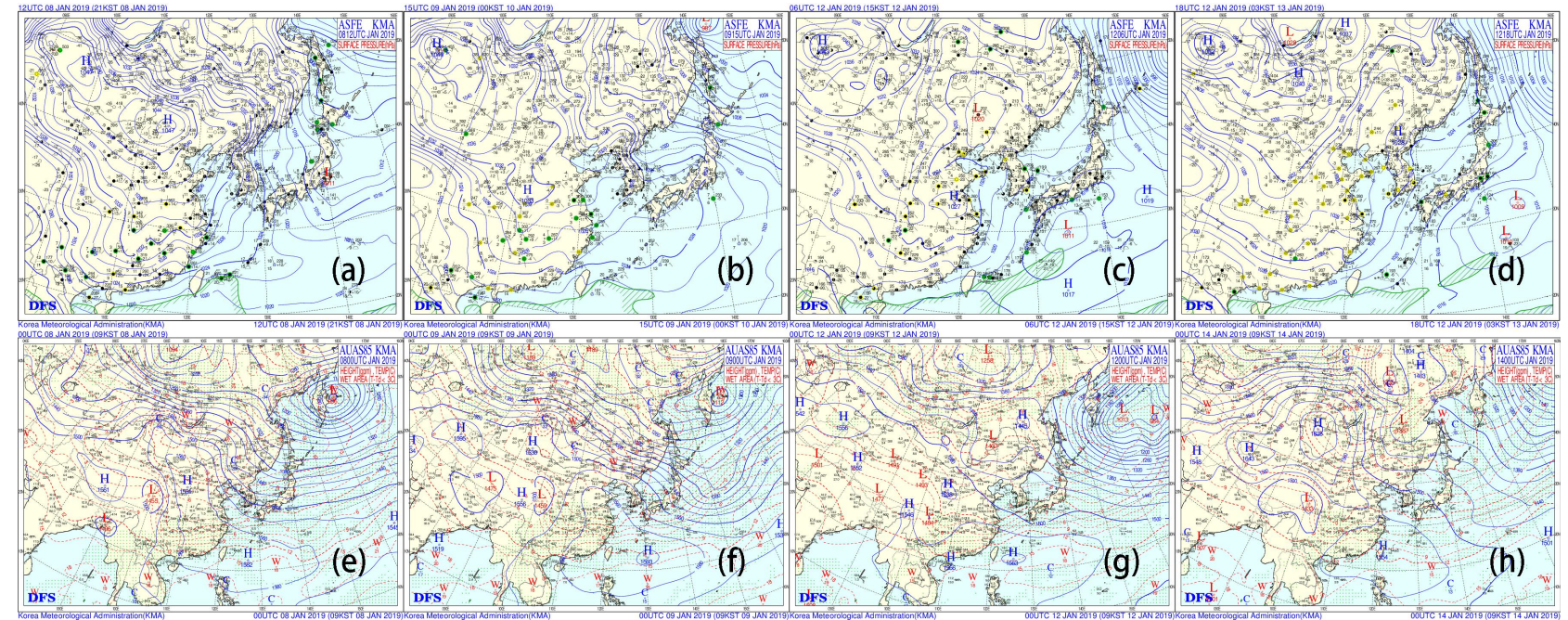

Fig. 3. Typical surface synoptic condition at (a)20:00 BT,8January, (b)23:00 BT,9January, (c)14:00 BT,12January, (d)02:00

BT,13January;850hpa pressure at (e)08:00 BT,8January, (f)08:00 BT,9January, (g)08:00 BT,12January, (h)08:00 BT,14January.

The synoptic condition during dispersion stage was roughly the same with the clean stage. At ground surface, Siberian cold and high-pressure system with a central pressure of $1043 \mathrm{hpa}$ dominated the Beijing and vicinity again (Fig. 3d). Therefore, there was a northeast wind occurring in the Beijing. Cold and relatively clean air mass swept away the air pollutants from Beijing. At the same time, dry and cold air mass reduced the temperature and humidity in Beijing, weakened the phenomenon of inversion and high humidity, and was more conducive to the gradual dissipation of haze. At the atmosphere height of $850 \mathrm{hPa}$, it could be found that the inland anticyclone high-pressure system with $1625 \mathrm{gpm}$ barometric center in the northwest of Beijing had a significant impact on Beijing and its surrounding areas (Fig. 3h). Beijing was located by the side of high-pressure ridge where cold and clean air mass spread violently toward northeast and southeast. In contrast, the subtropical high-pressure system over the western Pacific was gradually being weakened. Therefore, north wind appeared in Beijing, and the low-pressure cyclone with a barometric center of $1387 \mathrm{gpm}$ in the northeast region accelerated the north wind speed in Beijing. The low-pressure system with a barometric center of 1433gpm in the Qinghai-Tibet Plateau region also enhanced the high-pressure system in the northwest of Beijing, which formed wind shear and eventually Northwest wind. Relatively cold air mass carried the pollutants in Beijing and reduced the temperature at about 1500 meters above sea level. The weakened inversion is conducive to the vertical transport of air pollutants. Through horizontal and vertical diffusion, the haze phenomenon is gradually eliminated.

\subsection{Specific vertical structure of PBL}

Severe haze has stronger temperature inversion. The temperature inversion was more obvious at 08:00 BT and below $1500 \mathrm{~m}$ by comparison with 20:00 BT (Fig. 4 and Fig. 5) during 7 days. The surface temperature in the morning was lower than that in the evening as a result of the cooling caused by the surface thermal radiation at night, and the temperature difference between 08:00 BT and 20:00 BT on the same day was more than $5^{\circ} \mathrm{C}$. By comparing 9 January with 10 January, it is found that the overall temperature of 10 January increased significantly, and had an increment more than $5^{\circ} \mathrm{C}$ (Fig. 4a). There was more obvious temperature rise at higher level of PBL, such as, at a height of $500 \mathrm{~m}$, the temperature just rose by about $3^{\circ} \mathrm{C}$, but at a height of $700 \mathrm{~m}$, the temperature rose by about $7^{\circ} \mathrm{C}$ and 2.3 times than that at $500 \mathrm{~m}$. Therefore, the temperature inversion phenomenon was significantly enhanced. From 10 January to 14 January, the temperature in Beijing nearly unchanged. The temperature inversion reached the maximum on 13 January and the temperature at $1500 \mathrm{~m}$ was $19.9^{\circ} \mathrm{C}$ higher than that on earth surface. From 14 January to 15 January, the air temperature in Beijing dropped sharply again, and especially in the upper air, the temperature on 15 January was much lower than that on 9 January. The temperature difference between $1500 \mathrm{~m}$ and surface of 2 days decreased from $18.2^{\circ} \mathrm{C}$ to $3.5^{\circ} \mathrm{C}$. It is possible that the cold airflow was transmitted above $1500 \mathrm{~m}$. On 9 January and 15 January, Beijing was affected by inland high-pressure system. The cold air mass produced relatively clean northerly wind in Beijing, resulting in rapid cooling and a decrease in $\mathrm{PM}_{2.5}$ concentration. From 10 January to 14 January, western Pacific Subtropical Warm High-pressure system dominated Beijing, appearing south wind and rising temperatures in Beijing, and the air mass flow carried air pollutants from industries in southern Beijing, resulting in a growth in $\mathrm{PM}_{2.5}$ concentration. As the PBL stability increased, the temperature inversion became stronger. Under the stable inversion, the vertical exchange of turbulence was suppressed and the diffusion of air pollutants was hindered. 

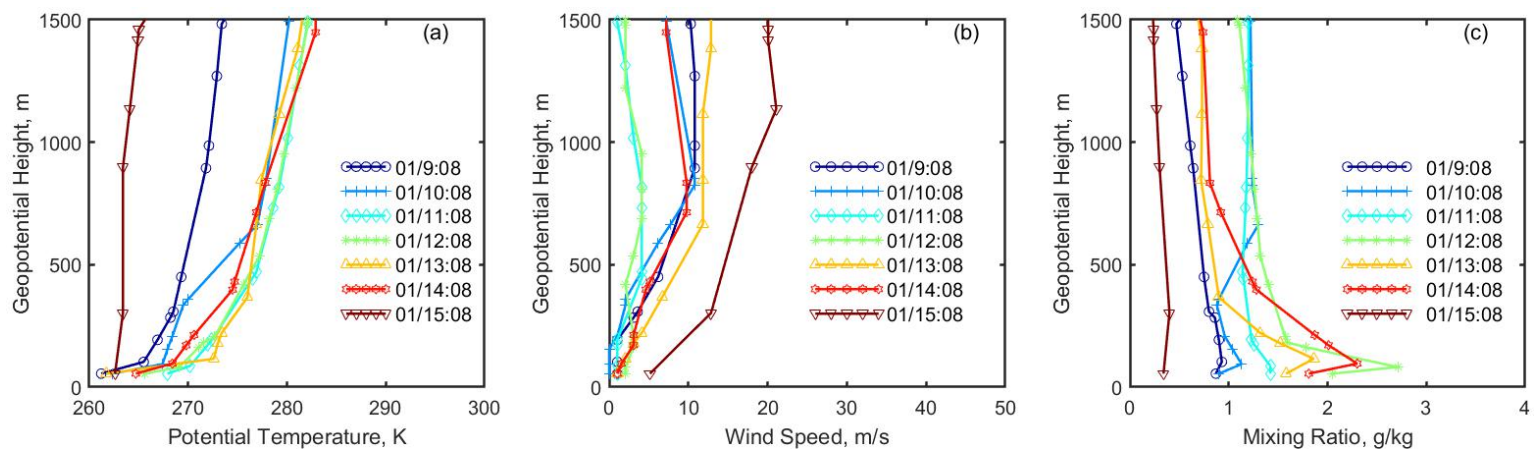

Fig. 4. Temporal variations in vertical distributions of meteorological factors from 9 January 2019 to 15 January 2019. (a) Temperature $(\mathrm{K}),(\mathrm{b})$ wind speed $(\mathrm{m} / \mathrm{s})$, and $(\mathrm{c})$ water vapor mixing ratio $(\mathrm{g} / \mathrm{kg}) .10-12$ January correspond to transport growth process, 12 - 13 January correspond to cumulative explosive growth processes.
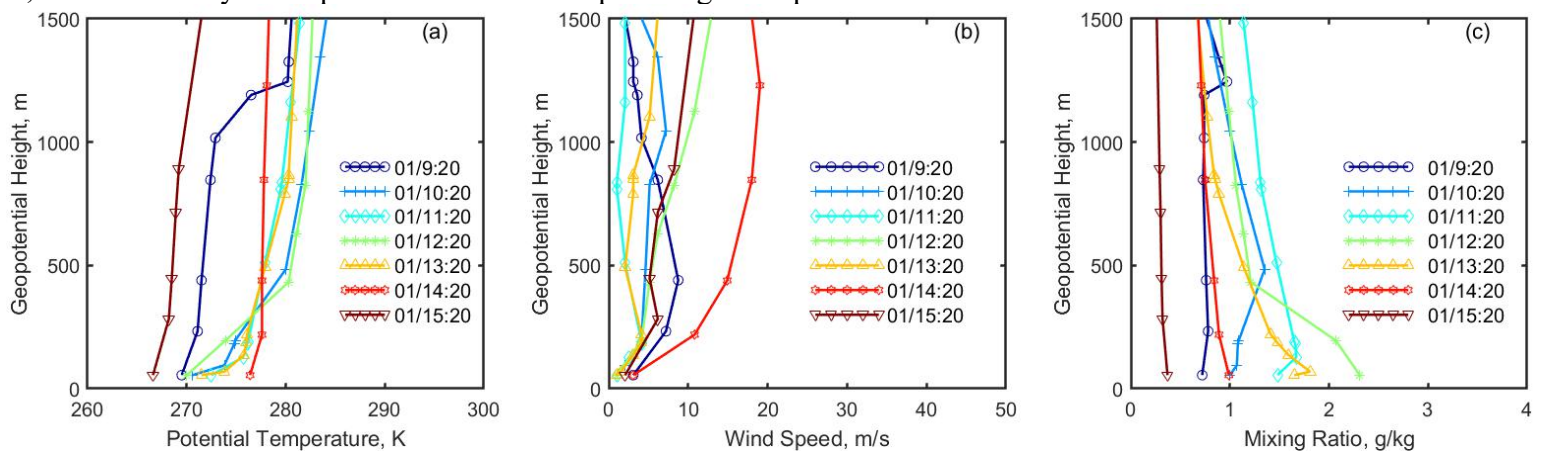

Fig. 5. Temporal variations in vertical distributions of meteorological factors at 20:00 BT from 9 January 2019 to 15 January 2019. (a) Temperature (K), (b) wind speed $(\mathrm{m} / \mathrm{s})$, and (c) water vapor mixing ratio $(\mathrm{g} / \mathrm{kg}) .10-12$ January correspond to transport growth process, 12 - 13 January correspond to cumulative explosive growth processes.

From the variation of the daily wind profile, it is seen that the wind speed in the range of from 0 to $1500 \mathrm{~m}$ generally increased according to rise of altitude (Fig. 4b). This is as a result of the structure of the PBL. When get closed the ground surface, the atmospheric friction is more serious. This friction drag is transmitted upward due to turbulence in the atmosphere and gradually decreases with the growing altitude, finally could be neglected when reaching a certain altitude. This height is called atmospheric PBL thickness. From 9 January to 14 January, the wind speed was relatively small, especially between 11 January and 12 January, low wind speed was conducive to the accumulation of $\mathrm{PM}_{2.5}$ in Beijing. In order to confirm this conclusion, it is found that 12 January is in the cumulative stage of $\mathrm{PM}_{2.5}$, and $\mathrm{PM}_{2.5}$ had a rapid explosive growth. Before 12 January, the concentration of $\mathrm{PM}_{2.5}$ increased continuously and the variation was in the transport stage. After January 14, the wind speed increased gradually again, corresponding to the dispersion stage of $\mathrm{PM}_{2.5}$. It is a conclusion that the variation of wind speed coincided with the characteristics of slow south wind and strong north wind. The wind in cumulative stage is relatively slow and simultaneously carried industrial emission from south of Beijing. Consequently, the advection transport of air pollutants decreased and $\mathrm{PM}_{2.5}$ was accumulated constantly. In contrast, the relatively clean and fast north wind is very conducive to the dissipation of haze. Wind shear provides kinetic energy for atmospheric turbulence. In haze days, the wind speed is relatively low, and the change of wind speed with height is small. The weakening of vertical wind shear is not conducive to the vertical exchange of air by atmospheric turbulence. At the same time, the decreased height of the PBL leads the higher aggregation degree of $\mathrm{PM}_{2.5}$. Lower wind speed at ground surface is more conducive to the accumulation of $\mathrm{PM}_{2.5}$ and local air pollutant is hardly to be blown away. Therefore, a great quantity of air pollutants accumulates frequently in a certain area.

By analysis of the variation of absolute humidity, the water vapor mixing ratio profile increases continuously from 9 January to 12 January (Fig. 4c). This period corresponded to the transport and accumulation of $\mathrm{PM}_{2.5}$. Similarly, the airflow during this period came from the south of Beijing. After 14 January, the humidity profile decreased entirely and the content of water vapor in the atmosphere was reduced. This period corresponded to the dispersion stage of $\mathrm{PM}_{2.5}$ and north wind. On 9 January and 15 January, the relatively low water vapor mixing ratio in the air demonstrated that the north air mass was generated by the north inland high-pressure system and had the feature of relatively dry and clean. From 10 January to 14 January, the air humidity was relatively high. Under $200 \mathrm{~m}$ altitude, the phenomenon of high humidity was more obvious, where the water vapor mixing was approximate $0.5 \mathrm{~g} / \mathrm{kg}$ higher than other periods. Atmospheric aerosol particles contain water-soluble materials. Therefore, these aerosol particles can absorb water and increase their volume with increasing relative humidity. The optical properties of aerosol particles are also changed ([25]). The hygroscopicity of aerosol particles determines the liquid water content of aerosol. Liquid water provides a medium for multiphase chemical reactions, leading to local photochemistry problems ([26-27]). Strong absorbent aerosols such as sulfate, nitrate, ammonium, and soluble organic particles tend to grow by absorbing moisture when the additional water vapor exists in the 
air ([28]). Normal $20 \%-60 \%$ of aerosol particle size is increased after moisture absorption in North China ([21]). Moreover, water vapor is conducive to the secondary reaction of sulfur oxides and nitrogen oxides in the air. The reaction produced a lot of sulfate and nitrate. Water vapor tends to adheres to particulate matter and these secondary reactions are liquid phase reactions. Particulate matter and water provide the reaction medium for the reactants. Secondary aerosols (inorganic and organic) are major components in fine particles in China ([29]). Along with the secondary reaction occurring, the concentration of $\mathrm{PM}_{2.5}$ goes up rapidly and the haze becomes more serious ([30]).

Above all, severe haze in Beijing is closely

\subsection{Spatial distribution of air pollution}

During the cleaning stage, the average concentration of $\mathrm{PM}_{2.5}$ in Beijing was about $24.8 \mu \mathrm{g} \mathrm{m} \mathrm{m}^{-3}$, which was obviously less than $35 \mu \mathrm{g} \mathrm{m}^{-3}$ and belonged to clean level. Except for the monitoring sites in the South and Northeast, the $\mathrm{PM}_{2.5}$ concentration of places other monitoring stations located was relatively low, and the air quality in the north was better than that in the south (Fig. 6a).

In the transport stage, it is found that the $\mathrm{PM}_{2.5}$ concentration in Beijing showed a downward trend spatially from south to north and from west to east (Fig. $6 \mathrm{~b})$. It suggests that air pollutants were transported from the southwest to Beijing through air flow. At this time, $\mathrm{PM}_{2.5}$ concentration increased significantly and the average $\mathrm{PM}_{2.5}$ concentration of 34 stations in Beijing was about $65.4 \mu \mathrm{g} \mathrm{m}^{-3}$ which was about 2.6 times of that during the clean stage. The concentration of $\mathrm{PM}_{2.5}$ in some areas of Southwest Beijing exceeded $80 \mu \mathrm{g} \mathrm{m}^{-3}$, which belonged to slightly polluted level. It is concluded that the concentration distribution of $\mathrm{PM}_{2.5}$ has obvious spatial characteristics.

The $\mathrm{PM}_{2.5}$ concentration in cumulative stage reached the maximum by explosive growth. During the cumulative stage, there is a finding that the $\mathrm{PM}_{2.5}$ concentration at all 34 stations was very high, especially in the southern part of Beijing (Fig. 6c). The $\mathrm{PM}_{2.5}$ concentration in the southern region was more than $500 \mu \mathrm{g} \mathrm{m}^{-3}$ and the average $\mathrm{PM}_{2.5}$ concentration in Beijing was $344.1 \mu \mathrm{g} \mathrm{m}^{-3}$. It belonged to the heavily polluted level. By comparing the monitoring concentration changes at each station from the transport stage to the cumulative stage, it is found that the $\mathrm{PM}_{2.5}$ concentration in eastern of Beijing increased more significantly than that in western region, and the pollutant concentration in northern China still remained relatively low. It is possible that air pollutants may be transported counterclockwise in Beijing and was centered on the downtown. This transport direction might be caused by wind shear which was produced by two opposite winds. The cold air mass is with the northeast wind and the warm air mass is with the southwest wind. This phenomenon is more conducive to the accumulation of pollutants in a specific area.

The $\mathrm{PM}_{2.5}$ concentration of dispersion stage in associated with meteorological condition. Strong temperature inversion and low wind speed increase the stability of the PBL and are not conducive to the turbulence transport of atmosphere. This phenomenon is more obvious at the height below $500 \mathrm{~m}$. The wind from the South has the characteristics of high temperature, relative slow wind speed and high humidity, and there are also numerous factories in the south of Beijing. High humidity accelerates hygroscopic growth and secondary reaction of aerosols. On the contrary, the north wind is less polluted and with low temperature, relative high speed, less water vapor. Consequently, it is conducive to the dissipation of haze.

downtown rarely declined (Fig. 6d). During the dispersion stage which was as a result of the cold air mass invading, the pollution concentration of places surrounding the urban area of Beijing decreased significantly. The reason is that the cold air from the north was relatively clean. The average $\mathrm{PM}_{2.5}$ concentration in Beijing was $264.7 \mu \mathrm{g} \mathrm{m}^{-3}$. The average $\mathrm{PM}_{2.5}$ concentration in north part of Beijing fell below $70 \mu \mathrm{g} \mathrm{m}^{-3}$ and only had little impact on human health. However, it is noteworthy that the $\mathrm{PM}_{2.5}$ concentration did not decrease significantly in the urban areas of Beijing. The $\mathrm{PM}_{2.5}$ concentration in urban areas remained around $450 \mathrm{\mu g} \mathrm{m}^{-3}$. This phenomenon might be caused by the relatively high buildings which obstruct the airflow transport. The building would increase the friction coefficient of the contact surface and consequently reduced the wind speed. Meanwhile, the exhaust was emitted by vehicles constantly in the city. Both factors were detrimental to the dissipation of haze. Wind is the main kinetic source of haze dissipation. However, the high buildings in cities weakened the role of wind, resulting in the retention and accumulation of air pollutants. Besides, the phenomenon of temperature inversion in urban areas was relative serious for the existence of building shadows which affected solar radiation, and the strength of inversion relates to surface albedo ([31]). The inversion layer could hinder the advection and vertical transport of air, leading the air pollutants rarely to diffuse upward. In recent years, the near-surface wind speed in Beijing has been getting lower ([32]) with stronger urban heat island effects ([33]), which is also not conducive to the dissipation of haze. The main reason for this phenomenon is that the urban surface structure has changed significantly as the remarkable increase of city scale. Urban reinforced concrete buildings absorb most of the solar radiation heat during the day, weaken the vertical atmospheric convection intensity during the day, and release heat stored at night, forming the urban heat island effect and urban atmospheric circulation. The urban heat island effect and urban atmospheric circulation is more obvious in the city with larger scale. The high intensity of urban atmospheric circulation could strengthen the resistance to external monsoon. 
(a)

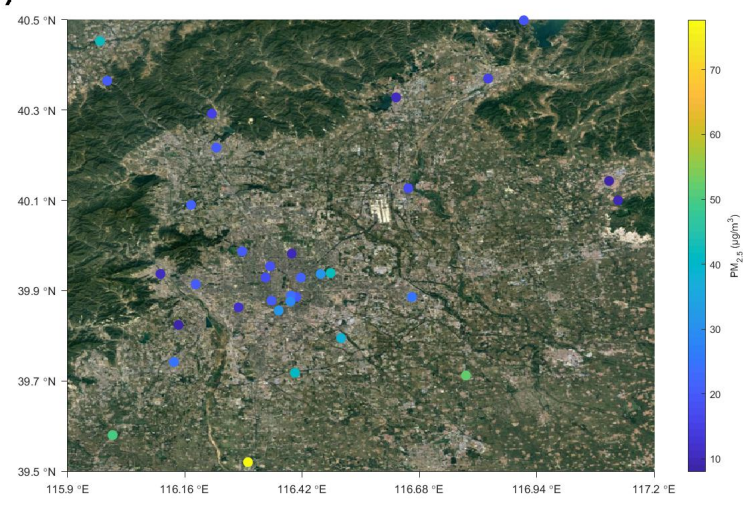

(c)

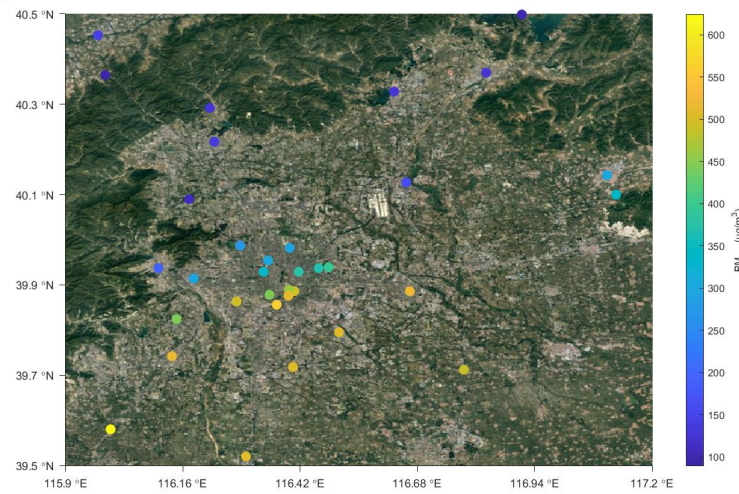

(b)

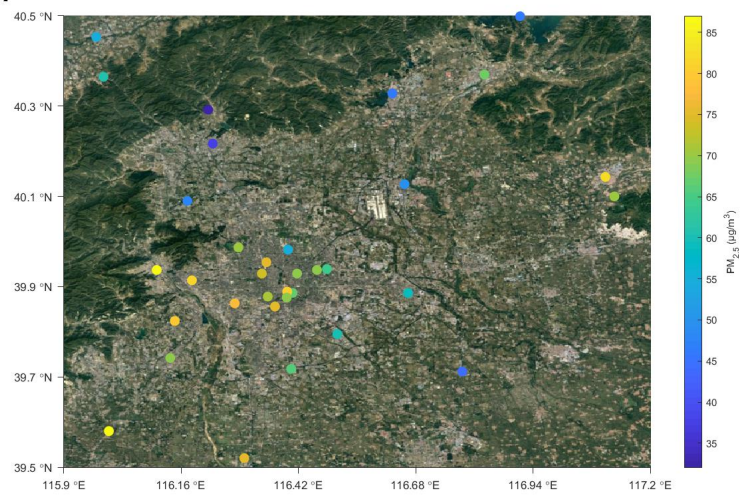

(d)

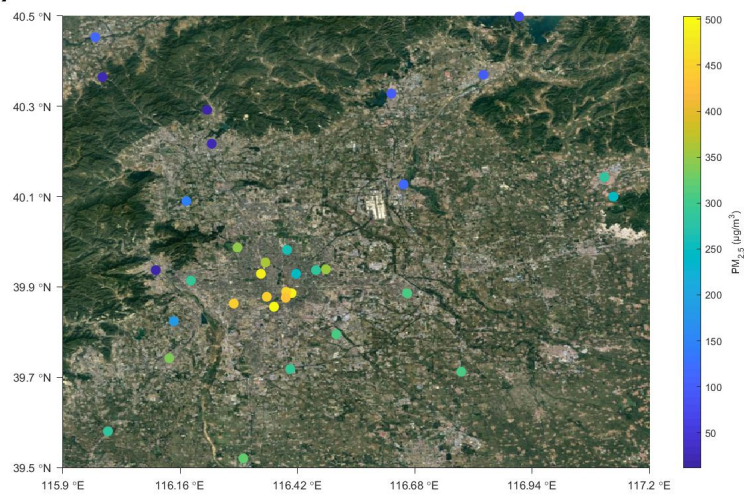

Fig. 6. $\mathrm{PM}_{2.5}$ concentrations of Beijing on 9 January BT 04:00-06:00 (a), 9 January BT 18:00-20:00 (b), 12 January BT 18:00-19:00 (c), and 13 January BT 04:00-5:00 (d).

\section{Conclusion}

Meteorological factor is the major cause of heavy haze pollution in Beijing and affected by synoptic variation. It is important to understand the comprehensive mechanism that different meteorological affects the $\mathrm{PM}_{2.5}$ concentration and how meteorological factors change with the variation in synoptic background. The $\mathrm{PM}_{2.5}$ spatial distribution is distinct in different stages accompanied with changed meteorological factors. To understand the extreme events, the air pollution case from 9 January to 15 January 2019 was selected. By analyzing the specific meteorological factors in clean, transport, cumulative and dispersion stage respectively corresponding to different $\mathrm{PM}_{2.5}$ concentration, three fundamental findings are revealed.

The haze of Beijing in winter was caused by unfavorable synoptic conditions and mainly controlled by the Siberian High-pressure and the Western Pacific Subtropical High-pressure. The western Pacific subtropical high system is the cause of haze and has the characteristics of high temperature, high humidity and low wind speed. Consequently, this south high-pressure system will produce the weather phenomena of inversion, high humidity and weak atmospheric turbulence in Beijing. This kind of synoptic condition could accelerate the secondary reaction of aerosol. Moreover, the southern wind carries air pollutants from factories in southern Beijing. Eventually, the concentration of $\mathrm{PM}_{2.5}$ experienced an explosive growth and severe haze occurred.

The meteorological parameters including temperature inversion, low near-surface wind speed and high humidity have substantial contribution to haze. Severe haze in Beijing was the comprehensive result of these factors interacting with each other. Concurrently, the PBL height reduced and the stability of PBL structure was strengthened. Stable PBL structure is inhibitive for the vertical and horizontal transport of air pollutant in atmosphere. Haze was hard to be eliminated.

The $\mathrm{PM}_{2.5}$ concentration in Beijing had obvious spatial distribution characteristics. The southern part of Beijing is close to factories, so the $\mathrm{PM}_{2.5}$ concentration is obviously higher than that in the northern part. During the dispersion stage, urban buildings and automobile exhaust inhibited the dissipation of haze in urban areas. The vehicle exhaust is one of the air pollutants sources. Building could partly block the spread of wind and building shadow is beneficial for temperature inversion by affecting solar radiation. The urban heat island effects to a certain extent makes the air pollution more serious in urban areas ([34]).

\section{Reference}

1. Wang, J. F., Hu, M. G., Xu, C. D., Christakos, G., and Zhao, Y.: Estimation of citywide air pollution in Beijing, PLoS ONE, 8(1), e53400- (2013), DOI: 
10.1371/journal.pone. 0053400

2. Peter, S., Holguin, F., Wood, L. G., Clougherty, J. E., Raederstorff, D., Antal, M., Weber, P., and Eggersdorfer, M.: Nutritional Solutions to Reduce Risks of Negative Health Impacts of Air Pollution, Nutrients, 7(12), 10398-10416 (2015), DOI: 10.3390/nu7125539

3. Laumbach, R, Meng, Q. Y., and Kipen, H: What can individuals do to reduce personal health risks from air pollution? Journal of Thoracic Disease, 7(1), 96-107 (2015), $\quad$ DOI: 10.3978/j.issn.2072-1439.2014.12.21

4. Wilson, A. M., Salloway, J. C., Wake, C. P., and Kelly, T.: Air pollution and the demand for hospital services: a review, Environment International, 30(8), $1109-1118 \quad$ (2004), $\quad$ DOI: 10.1016/j.envint.2004.01.004

5. Cao, C., Jiang, W. J., Wang, B. Y., Fang, J. H., Lang, J. D., Tian, G., Jiang, J. K., and Zhu, T. F.: Inhalable microorganisms in Beijing's $P M_{2.5}$ and $P M_{10}$ pollutants during a severe smog event, Environmental science \& technology, 48(3), 1499-507 (2014), DOI: $10.1021 /$ es4048472

6. Liu, Z. J., Zhu, Z. Q., Zhu, Y. X., Xu, W, and Li, H.: Investigation of dust loading and culturable microorganisms of HVAC systems in 24 office buildings in Beijing, Energy \& Buildings, 103, 166-174 (2015), DOI: 10.1016/j.enbuild.2015.06.056

7. Liu, Z. J., Li, H., and Cao, G. Q.: Quick Estimation Model for the Concentration of Indoor Airborne Culturable Bacteria: An Application of Machine Learning, International journal of environmental research and public health, 14(8), 857 (2017), DOI: 10.3390/ijerph14080857

8. Liu, Z. J., Cheng, K. W., Li, H, Cao, G. Q., Wu, D., and Shi, Y. J.: Exploring the potential relationship between indoor air quality and the concentration of airborne culturable fungi: a combined experimental and neural network modeling study, Environmental science and pollution research international, 25(4), 3510-3517 10.1007/s11356-017-0708-5

9. Wang, Y. S., Yao, L., Wang, L. L., Liu, Z. R., Ji, D. S., Tang, G. Q., Zhang, J. K., Sun, Y., Hu, B., and Xin, J. Y.: Mechanism for the formation of the January 2013 heavy haze pollution episode over central and eastern China, Science China Earth Sciences, 57(1), 14-25 (2014), DOI: 10.1007/s11430-013-4773-4

10. Zhang, Z. Z., Wang, W. X., Cheng, M. M., Liu, S. J., $\mathrm{Xu}, \mathrm{J} ., \mathrm{He}, \mathrm{Y}$. J., and Meng, F.: The contribution of residential coal combustion to $P M_{2.5}$ pollution over China's Beijing-Tianjin-Hebei region in winter, Atmospheric Environment, 159, 147-161 (2017), DOI: 10.1016/j.atmosenv.2017.03.054

11. MEP, 2015. 2014 report on the State of the Environment in China [online] Available from: MEP, Beijing, China, http://www.zhb.gov.cn/gkml/hbb/qt/201506/ W020150605383406308836.pdf.

12. MEP, 2016. 2015 report on the State of the
Environment in China [online] Available from: MEP, Beijing, China, http://www.zhb.gov.cn/gkml/hbb/qt/201606/ W020160602411685220884.pdf.

13. Zhong, J. T., Zhang, X. Y., Wang, Y. Q., Sun, J. Y., Zhang, Y. M., Wang, J. Z., Tan, K. Y., Shen, X. J., Che, H. C. ; Zhang, L., Zhang, Z. X., Qi, X. F., Zhao, H. R., Ren, S. X., and Li, Y.: Relative Contributions of Boundary-Layer Meteorological Factors to the Explosive Growth of PM2.5 during the Red-Alert Heavy Pollution Episodes in Beijing in December 2016, Journal of Meteorological Research, 31(5), $\quad 809-819$ (2017), DOI: 10.1007/s13351-017-7088-0

14. Zhong, J. T., Zhang, X. Y., and Wang, Y. Q.: Reflections on the threshold for PM2.5 explosive growth in the cumulative stage of winter heavy aerosol pollution episodes (HPEs) in Beijing, Tellus: Series B, Chemical and Physical Meteorology, 71(1), $\quad 1-7 \quad$ (2019), $\quad$ DOI: 10.1080/16000889.2018.1528134

15. Wang, H., Peng, Y., Zhang, X. Y., Liu, H. L., Zhang, M., Che, H. Z., Cheng, Y. L., and Zheng, Y.: Contributions to the explosive growth of $P M_{2.5}$ mass due to aerosol-radiation feedback and decrease in turbulent diffusion during a red alert heavy haze in Beijing-Tianjin-Hebei, China, Atmospheric Chemistry and Physics, 18(23), 17717-17733 (2018), DOI: 10.5194/acp-18-17717-2018

16. Li, W. G., Liu, X. G., Zhang, Y. H., Sun, k, Wu, Y. S., Xue, R., Zeng, L. M., Qu, Y., and An, J. L.: Characteristics and formation mechanism of regional haze episodes in the Pearl River Delta of China, Journal of Environmental Sciences, 63, 236-249 (2018), DOI: 10.1016/j.jes.2017.03.018

17. Zheng, G. J., Duan, F. K., Su, H., Ma, Y. L., Cheng, Y., Zheng, B., Zhang, Q., Huang, T., Kimoto, T., Chang, D., Pöschl, U., Cheng, Y. F., and He, K. B.: Exploring the severe winter haze in Beijing: the impact of synoptic weather, regional transport and heterogeneous reactions, Atmospheric Chemistry and Physics, 15(6), 2969-2983 (2015), DOI: 10.5194/acp-15-2969-2015

18. Zhu, X. W., Tang, G. Q., Hu, B., Wang, L. L., Xin, J. Y., Zhang, J. K., Liu, Z. R., Münkel, C., and Wang, Y. S.: Regional pollution and its formation mechanism over North China Plain: A case study with ceilometer observations and model simulations, Journal of Geophysical Research: Atmospheres, 121(24):14, 574-588 (2016), DOI: 10.1002/2016JD025730

19. Zhang, R. H., Li, Q., and Zhang, R. N.: Meteorological conditions for the persistent severe fog and haze event over eastern China in January 2013, Science China Earth Sciences, 57(1), 26-35 (2014), DOI: 10.1007/s11430-013-4774-3

20. Cheng, Y., He, K. B., Du, Z. Y, Zheng, M., Duan, F. $\mathrm{K}$., and Ma, Y. L.: Humidity plays an important role in the PM..5 pollution in Beijing, Environmental Pollution, 197, 68-75 (2015), DOI: 10.1016/j.envpol.2014.11.028

21. Pan, X. L., Yan, P., Tang, J., Ma, J. Z., Wang, Z. F., 
Gbaguidi, A., and Sun, Y. L.: Observational study of influence of aerosol hygroscopic growth on scattering coefficient over rural area near Beijing mega-city, Atmospheric Chemistry and Physics, 9(19), 7519-7530 (2009), DOI: 10.5194/acp-9-7519-2009

22. Zhang, Z., Xu, X., Qiao, L., Gong, D., Kim, S. J., Wang, Y., and Mao, R.: Numerical simulations of the effects of regional topography on haze pollution in Beijing, Scientific Reports, 8(1), 1-11 (2018), DOI: $10.1038 / \mathrm{s} 41598-018-23880-8$

23. Liu, X. G., Li, J., Qu, Y., Han, T., Hou, L., Gu, J., Chen, C., Yang, Y., Liu, X., Yang, T., Zhang, Y., Tian, H., and $\mathrm{Hu}$, M.: Formation and evolution mechanism of regional haze: a case study in the megacity Beijing, China, Atmospheric Chemistry and Physics, 13(9), 4501-4514 (2013), DOI: 10.5194/acp-13-4501-2013

24. Sun, J. J., Liang, M. J., Shi, Z. H., Shen, F. Z., Li, J. Y., Huang, L., Ge, X. L., Chen, Q., Sun, Y. L., Zhang, Y. L., Chang, Y. H., Ji, D. S., ; Ying, Q., Zhang, H. L., Kota, S. H., and Hu, J. L.: Investigating the PM 2.5 mass concentration growth processes during 2013-2016 in Beijing and Shanghai, Chemosphere, 221, 452-463 (2019), DOI: 10.1016/j.chemosphere.2018.12.200

25. Charlson, R. J., Schwartz, S. E., Hales, J. M., Cess, R. D., Coakley, J. A., Hansen, J. E., and Hofmann, D. J.: Climate forcing by anthropogenic aerosols, Science (New York, N.Y.), 255(5043), 423-30 (1992), DOI: 10.1126/science.255.5043.423

26. Ervens, B., Turpin, B. J., and Weber R. J.: Secondary organic aerosol formation in cloud droplets and aqueous particles (aqSOA): a review of laboratory, field and model studies, Atmospheric Chemistry and Physics, 11(21), 11069-11102 (2011), DOI: 10.5194/acp-11-11069-2011

27. Herrmann, H., Schaefer, T., Tilgner, A., Styler, S. A., Weller, C., Teich, M., and Otto, T.: Tropospheric aqueous-phase chemistry: kinetics, mechanisms, and its coupling to a changing gas phase, Chemical Reviews, 115(10), 4259-4334 (2015), DOI: $10.1021 / \mathrm{cr} 500447 \mathrm{k}$
28. Che, H., Zhang, X. Y., Xia, X., Goloub, P., Holben, B., Zhao, H., Wang, Y., Zhang, X. C., Wang, H., Blarel, L., Damiri, B., Zhang, R., Deng, X., Ma, Y., Wang, T., Geng, F., Qi, B., Zhu, J., Yu, J., Chen, Q., and Shi, G.: Ground-based aerosol climatology of China: Aerosol optical depths from the China Aerosol Remote Sensing Network (CARSNET) 2002-2013, Atmospheric Chemistry and Physics, 15(13), 7619-7652 (2015), DOI: 10.5194/acp-15-7619-2015

29. Yang, F., Tan, J., Zhao, Q., Du, Z., He, K., Ma, Y., Duan, F., Chen, G., and Zhao Q.: Characteristics of $P M_{2.5}$ speciation in representative megacities and across China, Atmospheric Chemistry and Physics, 11(11), 5207-5219 (2011), DOI: 10.5194/acp-11-5207-2011

30. Quan, J. N., Tie, X. X., Zhang, Q., Liu, Q., Li, X., Gao, Y., and Zhao, D. L.: Characteristics of heavy aerosol pollution during the 2012-2013 winter in Beijing, China, Atmospheric Environment, 88, 83-89 (2014), DOI: 10.1016/j.atmosenv.2014.01.058

31. Ruffieux, D., Wolfe, D. E., and Russell, C.: The Effect of Building Shadows on the Vertical Temperature Structure of the Lower Atmosphere in Downtown Denver, Journal of Applied Meteorology, 29(12), 1221-1231 (1990), DOI: 10.1175/1520-0450(1990)029<1221:TEOBSO $>2.0$. $\mathrm{CO} 2$

32. Zha, J. L., Wu, J., and Zhao, D. M.: Effects of land use and cover change on the near-surface wind speed over China in the last 30 years, Progress in Physical Geography, 41(1), 46-67 (2017), DOI: $10.1177 / 0309133316663097$

33. Qiao, Z., Tian, G. J., Zhang, L. X., and Xu, X. L.: Influences of Urban Expansion on Urban Heat Island in Beijing during 1989-2010, Advances in Meteorology (2014), DOI: 10.1155/2014/187169

34. Manju, A., and Abhinav, T.: Modeling of the urban heat island in the form of mesoscale wind and of its effect on air pollution dispersal, Applied Mathematical Modelling, 34(9), 2520-2530 (2010), DOI: $10.1016 /$ j.apm.2009.11.016 